\title{
A CONSTITUIÇÃO HISTÓRICA DO TRABALHO DOCENTE NO PERÍODO MILITAR
}

\section{THE HISTORY CONSTITUTION OF TEACHERS' WORK DURING MILITARY}

Kamylla Pereira Borges ${ }^{1}$

\begin{abstract}
RESUMO: Este texto pretende discutir a constituição histórica do trabalho docente mediante a implementação das Leis 5540/1968 e 5692/1971 e a relação entre trabalho e educação desenvolvidos no Regime Militar. Para tanto, partiremos de uma reflexão sobre os conceitos de trabalho e sua relação com a educação na perspectiva marxiana, para posteriormente apreendermos os nexos constitutivos do trabalho docente na ditadura militar. O que se percebe é que o trabalho docente foi constituído no período militar como um trabalho alienado. Isso pode ser demonstrado pelo controle parcial do seu processo de trabalho, a dicotomia entre o processo de elaboração e execução, entre a teoria e prática, e o controle rigoroso do Estado sobre a atuação do educador dentro e fora da sala de aula.
\end{abstract}

Palavras chave: Trabalho docente. Políticas públicas. Regime Militar.

\begin{abstract}
This text discusses the historical constitution of teachers' work (teaching) by the implementation of Laws 5540/1968 and 5692/1971 and the relationship between work and education developed in the Military Regime. To this end, we will leave of a reflection on the concepts of work and their relation with the education in the Marx's perspective for, later, to grasp the connections constituting the teachers' work in the military dictatorship. What is noticeable is that teachers' work was becoming, during military, as an alienated labor. This can be demonstrated by the partial control of their working process, the dichotomy between the preparation and execution process, between theory and practice, and strict control of the State over the actions of the educator inside and outside the classroom.
\end{abstract}

Keywords: Teachers' work (teaching). Public policy. Military Regime.

\footnotetext{
${ }^{1}$ Professora da Universidade Estadual de Goiás/ Unidade de Jaraguá, Mestre em Educação pela UFG - Universidade Federal de Goiás e Doutoranda pela UnB- Universidade de Brasília.
} 


\section{Introdução}

De acordo com Marx e Engels (2009) a história é a ciência que estuda como os homens em condições determinadas se relacionam entre si e com a natureza, para produzir trabalho e garantir sua subsistência de forma política, cultural e econômica. A história não é descontinua, mas é formada por um continuum em que alguns elementos do passado podem ainda se conservar no presente. Nesse sentido, Eric Hobsbawm (1998) nos chama a atenção para o fato de que através da história podemos descobrir os padrões e mecanismos que concorrem para a transformação das sociedades humanas, contribuindo para compreensão da realidade contemporânea.

Nesta perspectiva, apesar de hoje vivermos em um Estado de Direito dito democrático, os efeitos da ditadura militar, que controlou o país por cerca de duas décadas, ainda permanecem sobre a educação brasileira e consequentemente também sobre o trabalho docente, que continua marcado por um processo de proletarização, alienação e aligeiramento de sua qualificação profissional.

Assim sendo, este artigo pretende discutir a constituição do trabalho docente mediante a implementação das políticas educacionais e a relação entre trabalho e educação desenvolvidos no Regime Militar. Para tanto, partiremos de uma reflexão sobre os conceitos de trabalho e sua relação com a educação na perspectiva marxiana, para posteriormente apreendermos os nexos constitutivos do trabalho docente na ditadura militar.

\section{Conceito de trabalho, educação e o trabalho docente}

O trabalho é na maioria das vezes, visto como sinônimo de dor, sofrimento, desgaste físico e mental, mas na perspectiva marxiana, o trabalho é humanização, criação, recriação; é transformação dos elementos da natureza ao redor. Para Marx, o que distingue o ser humano dos outros seres é sua capacidade de ação transformadora consciente - a práxis. E o trabalho é, justamente, a manifestação da práxis. Ao trabalhar, o homem não apenas se reproduz intelectualmente, mas ativamente e em sentido real, pois ele vê a si 
mesmo no que foi produzido por suas próprias mãos. Assim, o trabalho é categoria fundante da humanização, é ontológico do ser humano, é através dele que a humanidade transforma sua própria realidade e forja suas condições materiais de existência (MARX, 2001).

O trabalho é um processo que permeia todo o ser humano e constitui sua especificidade, à medida que, pelo trabalho, o homem se produz e se reproduz. Ele é, antes de tudo, um processo entre o homem e a natureza; um processo em que o homem, por sua ação, medeia, regula e controla seu metabolismo com a natureza ao redor para satisfazer suas necessidades vitais básicas (MARX, 1988). Não há trabalho humano sem consciência e finalidade, na medida em que todo trabalho busca a satisfação de uma necessidade. Nesse sentido, Marx (1988) afirma que mais que o corpo físico preparado para trabalho, é necessária uma finalidade, uma consciência, um desejo, pois o processo de trabalho busca satisfazer as necessidades humanas, isto é, o trabalhador produz algo útil para prover sua própria existência.

Costa (1996), ao analisar o caráter teleológico do trabalho, afirma que este não pode existir sem uma finalidade especifica, pois em certo momento o processo de "hominização e humanização" não se concretizaria. Além disso, o trabalho é o que realiza a mediação entre o ser individual e o ser social (Mascarenhas, 2002). Pois, mais que relacionar-se consigo próprio e com a natureza, ao trabalhar, o homem relaciona-se com outros homens; assim, o trabalho é o elemento primordial na constituição de uma sociedade, já que propicia a própria sociabilidade humana.

Diante do exposto, segundo a teoria marxiana, o trabalho constitui a própria essência do homem, pois trabalhar é específico do ser humano, é o que o diferencia dos outros seres vivos. Todas as evoluções constatadas através dos séculos envolviam, de uma forma ou outra, o trabalho ou o trabalhador. Sua centralidade na vida humana é inegável. O trabalho é expressão e modelo de toda práxis humana - atividade transformadora consciente, criador e recriador da natureza, no qual estão fundadas a consciência, a linguagem e todas as relações sociais.

Sem trabalho, não há existência humana, pois é através dele que a humanidade garante sua sobrevivência. Mas, para trabalhar é necessário que o 
homem tenha conhecimento suficiente sobre a sua forma de produção, ou seja, é preciso que se saiba como produzir, quais elementos utilizar e para quais objetivos. É preciso que se aprenda como trabalhar e aqui nos deparamos com outro aspecto fundamentalmente humano, a educação. De acordo com Demerval Saviani (2007, p.154), o homem para se tornar homem precisa "aprender a produzir sua própria existência. Portanto a produção do homem é ao mesmo tempo a formação do homem, isto é, um processo educativo".

Aqui é importante que façamos uma consideração sobre o conceito de educação a que estamos nos referindo. Assim como Vitor Paro (2010) acreditamos que a educação consiste na apropriação da cultura, envolvendo informações, valores, crenças, ciência, arte, tecnologia, enfim todo o tipo de conhecimento que o homem produz ao intervir na natureza, visando a sua formação integral.

Ao trabalhar, o ser humano desenvolve uma atividade orientada para um fim, antes de pô-la em prática, ele imagina, planeja, idealiza suas ações e objetivos, criando seus próprios valores e satisfazendo assim suas necessidades. O homem se torna histórico, pois constrói sua própria historia através da produção de sua cultura, a qual é feita através do próprio trabalho. Dessa forma para se tornar homem, ele precisa apropriar-se da cultura historicamente produzida e é justamente a educação que realiza esse papel. "É pela apropriação dos elementos culturais que passam a constituir sua personalidade viva, que o homem se fez humano-histórico". (PARO, 2010, p.25)

Nesse sentido, como salienta Saviani (1991), a educação é um processo do e para o trabalho, existindo aí uma fundamentação histórico-ontológica na relação trabalho e educação. Isso porque, o ser humano não adquire sua subsistência de forma gratuita, ofertada pela natureza, ele precisa produzi-la por suas próprias mãos. E nesse processo de produção de sua vida material, ele se educa e educa novas gerações, isto é, o homem se forma homem. Dessa forma o trabalho e a educação se identificam em uma relação de reciprocidade, constituindo historicamente a própria humanização do homem.

Assim sendo, educação e trabalho mantinham nas comunidades primitivas uma total relação de identidade, onde um não poderia se realizar sem o outro. Nesse sentido, Aníbal Ponce (1986) afirma que a educação atendia aos 
interesses comuns de toda tribo, era espontânea e integral, pois não havia a institucionalização do ensino e todos eram educados de maneira que assimilavam os conteúdos, de forma quantitativa e qualitativamente satisfatória. Esse conceito de educação fundamentada no próprio processo de trabalho, espontânea e integral, atendendo a todos foi se extinguindo na medida em que a sociedade tornou-se dividida em classes.

A divisão do trabalho e o avanço das técnicas de produção repercutiram no poder de trabalho humano, passou-se a produzir mais, gerando um excedente de produtos, o que provocou a acentuação das diferenças econômicas da população. Concomitantemente, a propriedade comum foi substituída pela propriedade privada da terra, a partir daí ocorre uma nova configuração da sociedade, que passa a ser composta basicamente por duas classes distintas: os proprietários e os não proprietários. Surge assim a perspectiva de um novo modo de vida: a propriedade privada e o aumento da capacidade produtiva gerando uma produção de excedentes, possibilitou a uma determinada classe sobreviver sem precisar prover seu próprio sustento. O ócio estava instaurado e a partir dele novas possibilidades passariam a existir como o aperfeiçoamento cada vez maior dos instrumentos de trabalho, a cultura e as ideologias (PONCE, 1986; SAVIANI, 2007).

Dessa forma, a sociedade que antes era fundamentada em laços afetivos de sangue e na propriedade coletiva, agora passa a ser regida pela propriedade privada e os "vínculos de sangue retrocederam diante de um novo vinculo inaugurado: o que impunha poder do homem sobre o homem" (PONCE, 1986, p.25). Nesse contexto, onde os interesses comuns são substituídos por interesses particulares e distintos, é preciso instituir um novo tipo de educação que passaria a ser apreciada como fonte de poder e domínio, fortemente atrelada aos antagonismos das classes sociais.

Assim, educação e trabalho não mais permanecem juntos, se separam, ocorrendo uma quebra da unidade da educação, que antes se identificava com o próprio processo de produção, era espontânea e integral, atendendo a toda a sociedade de forma igualitária e total. Agora surgem dois tipos de educação: a educação da classe dominante e a educação da classe dominada. Aqui nós temos a origem da institucionalização do ensino e da escola propriamente dita. Aqueles 
que possuíam a propriedade da terra e consequentemente dispunham do ócio e tempo livre, era destinada uma forma de educação baseada em atividades intelectuais, na arte da palavra, nos exercícios físicos que se organizava na forma escolar. E para os não proprietários, a educação continuou ligada ao processo de trabalho. Assim, percebe-se que processos educativos estão completamente relacionados com as formas de produção da vida material. SAVIANI, 2007).

A partir daí, salienta Saviani (2007), a escola foi se complexificando, se aperfeiçoando até se constituir como parâmetro de todas as demais formas de educação. Assumindo na sociedade capitalista um papel fundamental na concretização desse modo de produção. Pois com a instauração de um novo sistema societal, era necessário uma nova forma de educação que forjasse uma nova concepção de mundo compatível com a nova ideologia capitalista. Era preciso a disseminação de uma moderna educação institucionalizada que levasse os sujeitos a assimilar atitudes, condutas e saberes que contribuíssem para manutenção e perpetuação desse sistema.

A educação institucionalizada, especialmente nos últimos 150 anos, serviu no seu todo- ao propósito de não só fornecer os conhecimentos e o pessoal necessário à máquina produtiva em expansão do sistema do capital, como também gerar e transmitir um quadro de valores que legitima os interesses dominantes, como se não pudesse haver nenhuma alternativa à gestão da sociedade, seja na forma "internalizada" isto é, pelos (indivíduos devidamente "educados" e aceitos) ou através de uma dominação estrutural e uma subordinação hierárquica e implacavelmente imposta. (MÉSZÁROS, 2008, p.35)

Assim, a educação, nesse contexto, tem respondido as demandas do modo de produção capitalista, contribuindo para formação de indivíduos resignados, dóceis e condicionados ao modelo societal do capital. Dessa forma, a socialização e apropriação da cultura, condicionantes fundamentais para humanização do homem, tem sido gestados no seio dessas relações sociais reproduzindo suas contradições, desigualdades e exploração. Aqui é importante salientar que as instituições educacionais possuem múltiplas determinações, sendo formadas historicamente por sujeitos que as constroem e reconstroem dia a dia, imersos em uma intrincada rede de relações que envolvem desde as políticas públicas para educação até os próprios alunos, pais e comunidade. Destes, 
especialmente, destaco o trabalho docente, que está intimamente ligado a própria produção dos processos educativos da escola capitalista, recebendo a grande responsabilidade de suprir as carências educacionais desta sociedade.

Sendo a educação a apropriação histórica da cultura, produzida através da atuação do homem na natureza, se caracterizando um processo do e para o trabalho, que tem como objetivo tornar os indivíduos humanos, tomamos como conceito de trabalho docente a ação voltada para produzir e disponibilizar intencionalmente os conhecimentos produzidos histórica e socialmente, visando a humanização do individuo singular. O trabalho docente é o esteio da escola, sem ele não há como a educação institucionalizada atingir seus objetivos. É ele que lida diretamente com os educandos, colocando-os em contato com os conteúdos e saberes necessários para sua atuação nessa sociedade.

O trabalho docente possui determinações históricas, sociais e políticas e não pode ser compreendido de forma isolada, mas dentro do contexto da sociedade em que está inserido. Assim sendo, o entendimento do movimento dialético da constituição e desenvolvimento do trabalho docente, suas contradições e tensões desenvolvidas ao longo de sua história no sistema societal do capital, nos revelam uma série de questões sociais, culturais, econômicas, políticas e ideológicas que determinam as atuais práticas pedagógicas desenvolvidas no interior das escolas. Dessa forma, continuaremos nossa análise focando os elementos que constituíram as condições do trabalho docente no período militar, o qual se constituiu como um importante marco histórico no Brasil, inclusive no que se refere à educação brasileira.

\section{O Regime Militar e as políticas educacionais}

Na década de 1960 o mundo vivia um período conhecido como guerra fria, fundamentada em uma intensa hostilidade entre os dois blocos detentores dos poderes econômicos e políticos mundiais liderados pela União Soviética e os Estados Unidos. A partir da Revolução Cubana, o Governo Norte Americano, na tentativa de ampliar sua influencia territorial, foi impelido a modificar sua política em relação aos paises da América Latina, e o então Presidente Kennedy instituiu 
a chamada "Aliança para o Progresso", visando alterar a estrutura econômicosocial dos paises latinos de terceiro mundo e consolidar a ideologia burguesa dominante em prol do modo de produção capitalista, impedindo a insurreição de novos movimentos revolucionários no continente.Com o assassinato de Kennedy, os Estados Unidos abandonam a política da "Aliança para o Progresso" e passam a investir na adoção de regimes ditatoriais sob a direção de militares, trazendo conseqüências diretas para o Brasil (FREIXO; ADJOVANES; 2002).

Assim, em 31 de março de 1964 em nome da luta contra o temível comunismo, uma manobra dos setores avançados da burguesia industrial brasileira, aliada aos grandes latifundiários do país, subsidiada pelo Governo Norte Americano e com o apoio das multinacionais e a intervenção executiva dos militares, deflagrou um golpe de estado que duraria duas décadas: o Regime Militar. Esse período foi marcado por grandes transformações no cenário político, econômico e cultural brasileiro, com intensas e violentas repressões com censura, perseguições, prisões, torturas e vários assassinatos, cuja manifestação mais contundente foi o Ato Institucional no 5 - AI-5. Além disso, vivia-se o chamado milagre econômico, fundamentado na modernização da indústria e setor de serviços e abertura ao capital estrangeiro. (GERMANO, 1993).

No cenário estabelecido pelo novo regime, onde se preconizava um novo modelo socioeconômico voltado para os interesses do capital internacional, eram necessárias modificações profundas nas políticas educacionais, que garantissem a funcionalidade da nova sociedade industrial emergente. Era preciso a configuração de um novo tipo de educação, que atendesse as demandas das grandes corporações nacionais e transnacionais estabelecidas no país. Além disso, a história do modo de produção capitalista nos mostra que há uma necessidade constante de adequação das políticas educacionais ao mercado, como forma de garantir a própria sobrevivência do sistema societal do capital. Romanelli (1994, p.59) salienta que

O capitalismo, notadamente o capitalismo industrial, engendra a necessidade de fornecer conhecimentos a camadas cada vez mais numerosas, seja pelas exigências da própria produção, seja pelas necessidades do consumo que essa produção acarreta. Ampliar a área social de atuação do sistema capitalista industrial é condição de sobrevivência deste. Ora, isso só é possível na medida em que as populações possuam condições mínimas de concorrer no 
mercado de trabalho e de consumir. Onde, pois, se desenvolvem relações capitalistas, nasce a necessidade da leitura e da escrita, como pré-requisito de uma melhor condição para concorrência no mercado de trabalho.

Por outro lado, era interesse dos adeptos ao golpe, formular uma política educacional que contribuísse para supressão ideológica de qualquer possibilidade resistência a ditadura militar instaurada. Nesse sentido e levando-se em conta o papel do Governo Norte Americano na instauração do Regime Militar, foram assinados os acordos MEC-USAID (Ministério da Educação e Cultura - United States Agency for International Development) que colocaria nas mãos dos técnicos da USAID a reorganização de todo sistema educacional brasileiro.

De acordo com Freixo e Adjovanes (2002), dois eixos nortearam a readequação da educação brasileira no interior desta aliança: a formação de mão de obra qualificada para ser absorvida pelas empresas nacionais e internacionais instaladas no país e a adequação ideológica do individuo a lógica do capital. A partir das orientações realizadas pelo acordo MEC-USAID foram realizadas as duas principais reformas educacionais da ditadura militar dando origem as leis $5540 / 68$ e 5692/71.

É interessante que aqui abramos um parêntese para compreender melhor o papel do Estado perante o sistema societal do capital. De acordo com Ângela Mascarenhas (2009) a atuação dos Governos está submetida à função desempenhada pelo Estado em uma determinada organização social. No caso da sociedade de sistema capitalista, o Estado não é de forma alguma independente ou autônomo, ele tem a missão primordial de sustentar o sistema societal do capital. Nesse sentido, as Políticas Púbicas são expressões incrementadas da finalidade do Estado.

Assim sendo, o Regime Militar diante do apogeu do crescimento urbanoindustrial e a instalação de empresas multinacionais no país, necessitava de uma nova mão de obra especializada, capacitada de acordo com as exigências do mercado. Para atingir esses objetivos, o governo estabeleceu uma vinculação direta entre a educação e o modo de produção capitalista e os princípios de racionalidade, eficiência e produtividade forma transportados da setor econômico e adaptados a educação. Tais princípios fundamentaram as Reformas do Ensino 
Superior e do primeiro e segundo graus. (FERREIRA JR; BITTAR, 2006; BRZEZINSKI, 1996).

Germano (1993) salienta que a política educacional do Regime Militar se desenvolveu em torno de 4 eixos principais: controle político e ideológico da educação escolar, estabelecimento de uma relação direta entre educação e produção capitalista, nos moldes da teoria do capital humano, descomprometimento com financiamento da educação pública e gratuita.

De acordo com os relatórios desenvolvidos pelos técnicos da USAID, era necessária a racionalização das Universidades brasileiras baseadas nos padrões empresariais capitalistas, além de um forte controle contra movimentos de protesto, enfatizando a hierarquia e autoridade. Esses relatórios nortearam todo processo de Reforma Universitária realizada em 1968. Esta teve como pontos principais: a extinção das cátedras, o estabelecimento da organização departamental, integração das atividades de ensino e pesquisa, divisão do currículo em 2 ciclos: um básico e outro profissionalizante e ênfase na pós graduação. (GERMANO, 1993)

Seguindo a lógica da Reforma de 1968, a ditadura militar inaugura em 1971 a Lei 5962, que unificou o antigo primário com o antigo ginásio formando o ensino de $1^{\circ} \mathrm{grau}$ e estabeleceu as diretrizes e bases para esse nível de ensino e também para o $2^{\circ}$ grau. Esta era fundamentada por dois pontos principais: aumento da escolaridade obrigatória e profissionalização compulsória generalizada a todo $2^{\circ}$ grau. Além disso, essa Reforma regulamentou a implantação dos cursos de licenciatura curta, voltado para formação de professores "polivalentes" em um prazo de cerca de 18 meses. (SAVIANI, 2008; GERMANO, 1993)

A Reforma de 1971 veio no contexto de grande euforia nacional, marcadas pelo forte crescimento econômico e a vitória do tricampeonato mundial de Futebol - A copa do Mundo de 1970. Por outro lado, vivia-se um período de intensa dominação e repressão política o que desarticulou os setores oposicionistas da sociedade civil. Nesse clima de consenso forçado e euforia, os professores aderiram de forma passiva à nova lei da educação básica, alguns foram inclusive, convidados pelo MEC para participar de cursos de especialização sobre a reforma, disseminando seus artigos e idéias para os restante do 
professorado. A política educacional pós-1964 foi uma expansão da dominação burguesa, viabilizada pela ação política dos militares, onde os interesses do capital prevaleciam em detrimento das necessidades dos trabalhadores (GERMANO, 1993).

Sem uma oposição contundente as políticas educacionais do período militar encontraram um caminho livre para serem implantadas em todo país, contribuindo ideologicamente para legitimação do governo instaurado. A educação se tornou submissa aos interesses do mercado, favorecendo uma formação alijada de conhecimentos voltados para o desenvolvimento de uma consciência crítica e um posicionamento político por parte dos indivíduos.

Além disso, a constituição de 24 de janeiro de 1967, desobrigou a União, Estados e municípios a dedicar um percentual mínimo de seu orçamento para financiamento da educação. Em conseqüência o governo federal foi reduzindo progressivamente os recursos destinados a educação. Além disso, Segundo Saviani (2008, p.299) "a Carta Magna do regime militar relativizou o principio da gratuidade do ensino, presente em todas as nossas cartas constitucionais, desde a primeira outorgada por Dom Pedro I, em 1824".

O aumento do número de alunos matriculados decorrente da ampliação de vagas nas escolas públicas preconizada pela Lei 5692/1971, longe de representar a democratização da educação brasileira, provocou uma deterioração da qualidade da educação básica. Não havia preocupação com fornecimento de condições adequadas para o desenvolvimento do processo de ensinoaprendizagem e a expansão da matricula assumiu um caráter meramente quantitativo. Devido a falta de instalações adequadas e o número reduzido de professores, na tentativa de manter 0 atendimento aos novos alunos matriculados e aqueles que já estavam na escola, optou-se pela diminuição da jornada escolar com aumento dos turnos. O que, unido ao pouco interesse do Estado em financiar a escola publica, favoreceu a deteriorização da qualidade da educação, pois apesar do aumento do acesso à escola pelas camadas populares, a educação oferecida era de "segunda categoria. Tanto é que as taxas de evasão e repetência mantiveram-se em níveis elevados." (GERMANO, 1993, p170).

Nesse sentido, percebe-se que a educação passa a ser definida por padrões aligeirados, utilitaristas e pragmáticos, adequada aos interesses do 
capital. Longe de contribuir para humanização do individuo, o sistema educacional do regime militar foi projetado para reprimir, alienar e desprover o indivíduo de qualquer tipo de conhecimento que concorra para sua emancipação. A relação entre educação e trabalho aqui não é mais humanizadora e nem omnilateral, mas totalmente unilateral e deformadora da humanidade do sujeito. Esse processo não atinge apenas os alunos, mas também todo contingente de professores, que devido as novas formulações, passam a ter que se adaptar a uma nova realidade da educação brasileira. Realidade esta marcada por profundas repressões, perseguições e desleixo com o financiamento da educação pública, propiciando uma escola onde predominam péssimas condições de trabalho e a precarização do professorado.

\section{A constituição do trabalho docente}

As reformas educacionais do período militar contribuíram para deteriorização das condições do trabalho docente. Principalmente por precarizar a formação dos professores, que se tornou aligeirada e desprovida de conteúdos pedagógicos consistentes e pela ausência de ações governamentais voltadas para implementação da carreira e remuneração do professor, provocando uma desvalorização social da profissão docente.

De acordo com Iria Brzenzinski (1996), até meados do golpe militar, a escola normal era o lócus fundamental de aprimoramento e formação dos professores, seja para atuar na escola fundamental ou na própria escola normal. Com advento das Reformas de 1968 e 1971, a escola normal perde esse status de escola e mesmo de curso e se transforma em uma das muitas habilitações profissionais do ensino de segundo grau, a denominada Habilitação Específica para o Magistério (HEM).

Tanuri (2000) salienta que a lei 5692/1971 adotava uma trama integrada e flexível para formação de professores. Dessa forma, a nova lei determinava que o ensino de $1^{\circ}$ a $4^{\circ}$ séries seria realizado por professores habilitados no $2^{\circ}$ grau, já o ensino da $1^{0}$ a $8^{\circ}$ séries seria realizado por aqueles detentores de habilitação especifica em nível superior, garantidas pelas chamadas licenciaturas 
curtas e o ensino de 1 e $2^{\circ}$ graus seria realizado por docentes possuidores de habilitação especifica de nível superior, correspondente a licenciatura plena. Além disso, os alunos que não possuíssem a licenciatura plena, poderiam realizar um curso em nível de complementação, com duração de um ano e se qualificar para o magistério até a $6^{\circ}$ série. Da mesma forma, os professores habilitados na licenciatura curta, após complementarem seus estudos, poderiam lecionar no 20 grau.

Os cursos voltados para formação de professores eram pautados em uma perspectiva de racionalismo e tecnicismo da produção e do ensino. Visavam formar técnicos, que no interior das escolas, qualificassem a mão de obra necessária para expansão do capitalismo no país. Nesse sentido, Romanelli (1994), observa que no processo de inserção do regime militar, a política educacional era composta por duas faces: eficiência, produtividade e desenvolvimentismo de um lado e controle e repressão de outro. Sendo que os padrões empresariais da teoria econômica vigente davam forma ao conteúdo e a utilização da força garantia a implantação do modelo.

No que diz respeito à formação em nível superior, a Reforma de 1968 trouxe conseqüências diretas para constituição do trabalho docente, principalmente porque provocou grandes transformações nos cursos de formação de professores. O currículo do curso de pedagogia foi modificado e seguindo as orientações da USAID, foi fracionado em habilidades técnicas, sendo esvaziado dos conteúdos críticos e de análise relacionadas à realidade socioeconômica brasileira, passando a ser voltado para formação dos chamados especialistas em educação. Reduzindo o curso de pedagogia a uma mera profissionalização descomprometida com a produção do conhecimento. (TANURI, 2000; BRZEZINSKI, 1996).

A tendência tecnicista em voga no período não perdoou o currículo da HEM, o qual era formado por um núcleo comum de formação geral e um voltado para formação especifica. No entanto, previa-se também a possibilidade da divisão do curso em habilitações específicas voltadas para atuação em duas ou mais séries do ensino fundamental, por exemplo: habilitação para o magistério em escolas maternais e jardins de infância, em 1 e $2^{\circ}$ séries, em 5 e 6 séries entre outras, com conteúdos específicos correspondentes a cada uma delas. Essa 
fragmentação promoveu uma diversificação das disciplinas especificas de cada habilitação, além da redução das cargas horária das disciplinas pedagógicas, com esvaziamento do curso em relação aos conteúdos pedagógicos contundentes. Outras críticas eram atribuídas a HEM, entre elas estavam: a separação entre teoria e prática, entre núcleo comum e parte profissionalizante, entre conteúdo e método e etc. (TANURI, 2000).

Essa formação categorizada e fragmentada provocava uma forte divisão do trabalho docente no interior das escolas. O planejamento das ações educativas ficava a cargo daqueles com formação em nível superior, os especialistas ou técnicos em educação e os professores advindos da Habilitação Específica para o Magistério (HEM) ficavam a cargo da execução do trabalho previamente já planejado. Ao ser regido pelo mercado, de acordo com os padrões para eficiência e produtividade, o trabalho docente perde sua autonomia, sua liberdade, sua consciência e se torna cada vez mais alienado, pois não há tempo para refletir, planejar ou analisar sua própria prática

A divisão do trabalho se constituiu como componente histórico-social indispensável à consolidação do seu controle. O trabalho dividido é facilmente controlado, coordenado e mais produtivo e, consequentemente, mais alienado, pois não permite o desenvolvimento integral do trabalhador nem do trabalho. 0 esfacelamento do trabalho docente faz com que o processo de tomada de consciência do trabalho como um todo não aconteça. E, assim, o professor fica alienado da compreensão do papel do seu trabalho na sociedade em que está inserido e na formação de seu aluno.

Marx (1985) afirma que a divisão do trabalho faz com que o este perca seu caráter especial e integral. O trabalho torna-se atividade desprovida de sentido, na medida em que seu processo é esfacelado e distribuído aleatoriamente entre diversos trabalhadores, que perdem a compreensão sobre o quê estão fazendo e o porquê. Assim, a divisão do processo de trabalho docente, manifesta principalmente pela dicotomia entre planejamento e execução das ações pedagógicas, contribuiu de forma contundente para que a atuação do professor na escola se tornasse alienada. Nesse sentido, no período militar o trabalhador docente se encontrava em meio um processo de forte controle, submissão, divisão e parcelamento do trabalho, o que dificultava o 
desenvolvimento de um posicionamento político e crítico tanto por parte dos professores quanto dos alunos.

Trabalho alienado em Marx pode ser definido como o estranhamento do trabalhador em relação ao trabalho realizado, ao produto do trabalho e a ele mesmo. Entendemos que o estranhamento é o afastamento do homem de sua essência humana, é a sua conversão em coisa, sua reificação. O trabalho se torna externo, não faz parte da natureza do trabalhador. Traz um sentimento de sofrimento ao invés de bem estar, o trabalhador não está mais livre para manifestar seus desejos e satisfazer suas necessidades através de sua própria produção, mas aprisionado, contrafeito, física e emocionalmente deprimido. (MARX, 2001).

O trabalho alienado escraviza o homem, deteriora sua identidade como sujeito de uma coletividade, atomiza as relações humanas propiciando a exacerbação da concorrência e da competição, nega ao trabalhador a capacidade de reger seu próprio processo de produção e o expropria do que ele próprio produziu. Transforma o trabalho, fonte de riqueza e humanização, em sinônimo de dor, sofrimento, tortura, pobreza e desumanização, tornando os homens semelhantes aos animais e cada vez mais explorados uns pelos outros.

Além disso, a expansão das matriculas provocou a necessidade da contratação de novos professores para atuar na educação pública. E aqui, Ferreira Jr e Bittar (2006) salientam que houve uma alteração da classe social a qual pertencia os trabalhadores docentes brasileiros. Os professores que antes se identificavam com os profissionais liberais como médicos e advogados, advindos da classe média alta, agora passam a serem formados por um contingente advindo das classes médias baixas ou das camadas dos trabalhadores urbanos. Estes enxergaram no processo de expansão da oferta de vagas para cursos voltados para formação de professores, a possibilidade de ascensão de seu status social e melhora de sua qualidade de vida econômica.

Dessa forma, estes autores afirmam que as políticas educacionais do Regime Militar ocasionaram uma alteração na constituição histórica do trabalho docente, que passou a ser definido por professores advindos da classe trabalhadora. Estes foram marcados pela formação aligeirada, arrocho salarial e 
péssimas condições de trabalho, advindas principalmente pela redução drástica do investimento do governo com educação pública.

Em relação a desqualificação da educação brasileira e consequentemente do trabalho docente, Vitor Paro (2006, p.131), afirma que

\begin{abstract}
Como acontece em qualquer processo de produção, na medida em que o bem ou serviço a ser produzido pode ser de qualidade bastante inferior, passa-se a utilizar, em sua elaboração, meios de produção e mão-de-obra de qualidade também inferior, os quais estão disponíveis estão disponíveis, geralmente em maior quantidade e a preços mais baixos. No processo de degradação das atividades profissionais do educador escolar, com a conseqüente desqualificação de seu trabalho e o aviltamento de seus salários, deu-se algo de semelhante: na medida em que não interessava à classe detentora do poder político e econômico, pelo menos no diz respeito à generalização para as massas trabalhadoras, mais que um ensino de baixíssima qualidade, o Estado, como porta voz dos interesses da classe, passou a dar cada vez menor importância a educação pública, endereçando para aí recursos progressivamente mais insuficientes e descurando cada vez mais das condições em que se realizava o ensino de massa. Tudo isso gerou a multiplicação de classes super lotadas, recursos didáticos precários e insuficiente, precaríssima qualificação profissional e baixíssima remuneração do professor.
\end{abstract}

Portanto, o trabalhador docente no período militar foi alvo de uma intensa precarização. O aligeiramento dos cursos de formação e qualificação profissional dos professores, aliados ao tecnicismo e divisão do trabalho encontrada no interior das escolas, queda da remuneração e inexistência de um plano de carreira, tornaram os docentes vítimas de um intenso processo de proletarização. A proletarização é aqui entendida como o empobrecimento de suas condições de trabalho. E assim como os demais trabalhadores do sistema societal do capital, os professores desenvolviam um trabalho alienado, pois não possuíam o controle de seu processo de trabalho e nem se identificavam com o produto do mesmo. Dessa forma, os professores perderam seu caráter de sujeito da práxis, da transformação social da realidade e foram aprisionados pelos interesses da ditadura militar vigente. 


\section{Considerações Finais}

O trabalho docente, apesar de suas particularidades, foi historicamente construído dentro do modo de produção capitalista do Regime Militar como um trabalho alienado. Isso pode ser demonstrado pelo controle parcial do seu processo de trabalho, a dicotomia entre o processo de elaboração e execução e entre a teoria e prática, o controle rigoroso do Estado sobre a atuação do educador dentro e fora da sala de aula.

Além disso, o trabalho do professor era pautado em uma relação entre educação e trabalho fundamentada na submissão aos interesses do mercado capitalista. Essa relação gerou um sistema educativo fragmentado, pragmático e utilitarista, desvinculado de toda e qualquer formação para a transformação social, mas exclusivamente voltada para manutenção ideológica do sistema ditatorial vigente.

Diante dos aspectos mencionados o professor, fortemente reprimido e controlado pelo Estado, acaba perdendo seu potencial critico e sua consciência política, deixando de ser, de acordo com a teoria marxiana, o sujeito da práxis voltado para a transformação social e emancipado através do trabalho e transformando-se em um objeto, para ser usado de acordo com interesses do regime militar.

No entanto, não podemos deixar de mencionar que apesar de submetidos a essas condições degradantes e alienantes do trabalho, nem todos trabalhadores docentes da época se resignaram de forma tão passiva. Muitos foram à luta em prol de condições dignas de trabalho e de vida. O que mais tarde contribuiu com derrocada do sistema e a inauguração de um novo processo histórico no Brasil. 


\section{Referências}

BRZEZINSKI, I. Pedagogia, Pedagogos e formação de professores. Campinas, SP: Papirus, 1996.

COSTA, S. O trabalho como elemento fundante da humanização. Revista Estudos, Goiânia: UCG. v. 22, n. 3/5. dez/1996, p.171-188.

FERREIRA JR, A; BITTAR, M. A Ditadura Militar e a proletarização dos professores. Educação e sociedade. Campinas, v. 27, n. 97, set/dez 2006. p. 1159-1179.

FREIXO, A.; ADJOVANES, T. S. A. Os acordos MEC-USAID e a reestruturação do sistema educacional brasileiro. In: $X$ Encontro Regional de História. ANPUH-RJ, Histórias e Biografias. Universidade do Estado do Rio de Janeiro, 2002.

GERMANO, J. W. Estado Militar e educação no Brasil (1964-1985). São Paulo; Cortez, 1993.

HOBSBAWM, E. J. Sobre história. São Paulo: Companhia das Letras, 1998.

MASCARENHAS, A. C. B. XVII Simpósio de Estudos e Pesquisas da Faculdade de Educação. UFG. Mesa Redonda: Governos "pós-neoliberais" na América Latina e Educação. Revista Interação. v. 34, n. 1, 2009. p. 2-6.

O trabalhador e a identidade política da classe trabalhadora. Goiânia: Alternativa. 2002

MARX, K. Manuscritos econômico-filosóficos. São Paulo: Martin Claret, 2001.

MARX, K; ENGELS, F. A ideologia alemã. São Paulo: Expressão Popular, 2009.

MARX, K. O Capital. Livro 1, v.1. São Paulo: Nova Cultural, 1988.

Miséria da Filosofia. São Paulo: Global, 1985.

1997. O 18 Brumário e cartas a Kugelmann. Rio de Janeiro: Paz e Terra,

MESZÁROS, I. A educação para além do capital. São Paulo: Boitempo, 2005.

PARO, V. H. Administração Escolar: introdução crítica. 14 ed. São Paulo: Cortez, 2006.

- Educação como exercício de poder: crítica ao senso comum em educação. 2 ed. São Paulo: Cortez, 2010.

PONCE, A. Educação e Luta de Classes. 7 ed. São Paulo: Editora Cortez, 1986.

ROMANELLI, O. T. de O. História da educação no Brasil 1930/1973. 16 ed. Petrópolis: Vozes, 1994. 
SAVIANI, D. O legado educacional do Regime Militar. Cad. Cedes, Campinas, v. 28, n 76, set/dez 2008, p. 291-312.

Associados, 1991

Pedagogia histórico-critica. 7 ed. Campinas, SP: Autores - Trabalho e educação: fundamentos ontológicos e históricos. Revista brasileira de Educação, v. 12, n. 34. jan/abril 2007.

TANURI, L. M. História da formação de professores. Revista Brasileira de Educação. São Paulo, n. 14, mai/ago 2000.

Recebido em 02 de dezembro de 2012.

Aprovado em 30 de junho de 2014. 